\title{
Determinants and Growth Effect of FDI in South Asian Economies: Evidence from a Panel Data Analysis
}

\author{
T.Bhavan (Corresponding author) \\ Doctoral Degree Candidate, School of Economics, Huazhong University of Science and Technology (HUST) \\ 1037, Luoyu Road, Wuhan, P.R.China \\ E-mail: ttbhavan_ecn@yahoo.com
}

Changsheng $\mathrm{Xu}$

School of Economics, Huazhong University of Science and Technology (HUST)

1037, Luoyu Road, Wuhan, P.R.China

E-mail: chshxu@hotmail.com

Chunping Zhong

School of Economics, Huazhong University of Science and Technology (HUST)

1037, Luoyu Road, Wuhan, P.R.China

E-mail: cpzenith@163.com

\begin{abstract}
This empirical study investigates the determinants and growth effect of FDI in case of four South Asian countries over the period of 1995-2008. It comprises two major analytical parts. Firstly, we incorporate a gravity model equation in order to investigate potential determinants of foreign direct investment in these countries. Secondly, we use a growth model equation to investigate growth effect of foreign direct investment in the countries. For both analyses, we use panel data and employ Arellano-Bond dynamic panel system method of moment estimator. The results derived from this study suggest that: (1) the pulling, pushing and cyclical factors are crucially important in determining FDI in South Asian countries; (2) foreign direct investment in South Asian countries is significant and positively associated with growth rate, but seems to be having average supportive to the growth rate in these countries.
\end{abstract}

Keywords: Determinants, FDI, Growth rate, Gravity model, South Asia

\section{Introduction}

Following liberalization policies initiated by most of the South Asian countries in 1990s and early 2000s; these countries have been great attention of developed and emerging economies associated with moving FDI into this region. As a result, the recent years have witnessed a tremendous rise in FDI in the region. Consequently, researchers and policy makers have initiated paying attention on the studies on FDI with respect to these countries' economies. In that way, this study also enters the stream investigating determinants and growth effect of FDI considering four South Asian economies. In this study, South Asian used to refer Pakistan, India, Bangladesh and Sri Lanka. As far as the home countries and trend of FDI in the region is concerned, presently South Asian countries are becoming important destinations of the leading sources of FDI such as U.K, U.S.A, Mauritius, Netherlands, Singapore, Germany, France, Japan, Republic Korea, Switzerland, Japan, China, Singapore, Saudi Arabia, Germany, United Arab Emirates, Malaysia, Canada, Egypt and Norway (ADB, 2007). These home countries have increased their private investment in South Asia, especially after 2000s. The figures 1-4 show that FDI inflow as a percentage of GDP has tremendously increased in South Asian countries, more specifically; in India it starts to increase in 2003 and shows a sharp increase after 2005 while it happens in 2003 in Pakistan. In Sri Lanka, the FDI steadily increases from 2001 and experiencing a sharp increase after 2005 as well. FDI in Bangladesh highly fluctuates, but shows increasing trend after 2003. Therefore, this empirical study takes interest investigating determinants and growth effect of FDI in these countries.

\subsection{Determinants of FDI}

Though the South Asian countries show tremendous increase in FDI in recent years, the FDI in these countries is relatively low compared to other Asian countries (ADB, 2007). At this juncture, the questions that should be 
emphasized that what principle factors that determine FDI inflow or what factors being attractive for FDI inflow and what motivate home countries to move private investment towards host countries. The countries with sustain robust growth level with impressive share of service sector, its large domestic market which can attract foreign companies to establish large production bases for this market and its policy reform in favour of attracting FDI results higher FDI inflow into the host countries. Using pooled cross-section and time-series data for 49 less-developed countries over 1970-95, Gastanagav et al. (1998) examined the effects of several different types of policy and institutional variables, including corporate tax rates, tariff rates, the degree of openness to international capital flows, exchange rate distortions, contract enforcement, nationalization risk, bureaucratic delay and corruption, suggest that host country policies can influence FDI flows primarily through their influence on the advantages of location in the host country. Frenkel (2004), investigating FDI flow between major industrial countries and 22 emerging economies adopting a gravity model using panel data, suggested that distance and both home and host country characteristics play significant role in determining the extent of FDI flows. Wei (2005) studied the determinants of inward FDI in China and India, and the causes for their huge difference, found that China's much higher FDI from OECD countries is mainly due to its larger domestic market and higher international trade ties with OECD countries while India has advantage in its cheaper labor cost, lower country risk, geographic closeness to OECD countries, and cultural similarity. Bellak et al. (2008), using panel-gravity model approach, investigated the determinants of FDI across the selected Central and Eastern European Countries (CEECs), focusing on labor costs, propose that a labor cost measure which is relevant for the location decisions of Multinational Enterprises. Xing (2006), examining the critical role of Chinese currency against Japanese Yen in FDI boom in the country, found that devaluation of the Yuan (Renminbi) and the policy of pegging the Yuan to the Dollar both improved China's competitiveness in attracting Foreign Direct Investment. Further, the real exchange rate between the Yuan and Yen is one of the significant variables determining Japanese direct investment in China.

Though, theoretically and empirically, there are factors that determine FDI have already been identified in a number of studies, the significance and magnitude of their impact on FDI may wary in terms of their national political, economic and legal cultures, traditions and infrastructures, together with the economic objectives and policies pursued by host governments ( Bitzenis et al., 2009). At this context, we believe that the studies on investigating determinants of the FDI and subsequently, concentrating on maximizing effort of the factors that turn FDI as potential and effective are essential in case of these countries. Thus, as first part of this study, we focus on investigating the determinants and their magnitude of effect on FDI in South Asian region.

\subsection{Growth effect of FDI}

Since recent years have been witnessed as a tremendous increase in FDI in South Asian countries, as second part of this study, we examine magnitude of growth effect of FDI associated with these countries. FDI increases capital stock, organizational restructuring, technology transfer and productivity, these results in inducement in growth rate, especially in host countries. Though, FDI is seen as a vital factor in inducing growth rate, however, it will only lead to growth if its inflows are properly managed (Bezuidenhout, 2009). FDI is identified as a vital requirement factor for sustain growth in developing economies which is mostly transfer of capital from developed and emerging economies to these countries benefiting global economies as a whole. FDI can accelerate growth in the ways of generating employment in the host countries, fulfilling saving gap and huge investment demand and sharing knowledge and management skills through backward and forward linkage in the host countries (Frenkel et al., 2004). Foreign direct investment also plays an extraordinary and growing role in global business. For a host country, it can provide a firm with new markets and marketing channels, cheaper production facilities, access to new technology, products, management skills and financing, and as such can provide a strong impetus to economic development (Mordechai et al., 2008). Smarzynska (2004) demonstrated that knowledge spill over occurs not only from MNCs to domestic industry but also among the intra industries. (Beugelsdijk et al., 2008) suggested that the transfer of advanced technology strengthens the host country's existing stock of knowledge through labor training, skill acquisition, the introduction of alternative management practices and organizational arrangements. Solow (1957) devised a framework for distinguishing the contributions of labour, capital and technological change to economic growth. Although the Solow growth formula had indicated a comparatively minor role to the capital input in overall growth, he emphasized that productivity growth may not be independent of the rate of investment activity, means that technical progress may be embodied in the act of investment. He further pointed out that the role of multi-national enterprise as a vehicle for the transmission of technical progress to the less advanced economies. Kenneth Arrow (1962) incorporating the concept of learning by doing, and his concept extended by Levhari (1966) and Sheshinski (1967) also emphasized that each firm learn from the investment activity of other firm as well as from its own investment behavior. As alternative attempt of explaining technological change endogenously Uzawa (1965), Lucas (1988) and Romer (1990) stressed that human capital is crucial determinant in the growth process. 
Roomer (1995) argues that an important part of this technology is the idea or blueprints concerning how to produce new goods, how to increase quality, or how to reduce costs (Acemoglu, 2008). As contrary, Herzer et al.. (2007) has argued that with 28 developing countries data there exists neither a long-term nor a short-term effect of FDI on growth; in fact, there is not a single country where a positive unidirectional long-term effect from FDI to GDP is found. Whalley and Xin,(2009) examined the contribution of inward FDI to China's recent rapid economic growth using a two stage growth accounting approach and suggested that the sustainability of both China' export and overall economic growth may be questionable if inward FDI plateaus in the future. Tuan et al.. (2009) investigated the role of inward FDI in the process of regional development and the economic growth and as one of their major findings, suggested that FDI affects not only output growth and productivity progress directly but also indirectly, that is, growth increases through the total factor productivity (TFP) enhancement. Yao and Wei (2007) discussed growth effect of FDI by testing two propositions that the role of FDI promoting production efficiency and technology, and knowledge, concluded that FDI is a powerful driver of economic growth for a newly industrializing economy, under these two propositions, to catch up with the world's most advanced countries. Chakrabory and Nunnenkamp (2008) analyzed sectoral growth impact of FDI in case of India and found that FDI in the service sector appears to have promoted growth in the manufacturing sector through cross-sector spillovers and thus economic growth. Alfaro et al, (2004) examined growth effect of FDI in OECD countries when these countries have better financial system; found that FDI alone plays an ambiguous role in contributing to economic growth. However, countries with well-developed financial markets gain significantly from FDI. Borensztein et al.. (1998) tested the effect of FDI on economic growth in a cross-country regression framework, utilizing data on FDI flows from industrial countries to 69 developing countries over the last two decades, suggested that FDI is an important vehicle for the transfer of technology, contributing relatively more to growth than domestic investment. Ma (2009) investigated growth effect of FDI and concluded that foreign capitals exert positive effects on the national economic growth. Merican (2009) tested the impact of FDI and Gross Domestic Investment on growth in case of four Asian countries, suggested that the FDI is better than Domestic Investment for growth only in two countries.

As second part of this study, this paper is also strongly intended to investigate how far FDI affects growth rates in South Asian countries as well. In this respect, this study focuses on investigating the determinants and growth effect of FDI flow, by adopting gravity and endogenous growth models, respectively, in case of Bangladesh, India, Pakistan and Sri Lanka, by employing the system generalized method of moments (GMM) estimation. The rest of the paper is structured as follows. Section 2) presents data and methodology which includes empirical model specifications and methods of analyses. Section 3) presents results and interpretation. Section 4) summarizes the main findings and offers some conclusions.

\section{Data and Methodology}

The data set drawn from two different sources comprises time series data of four countries for the period of 1995-2008. The data on FDI drawn from UNCTAD database while dataset for other variables comes from World Bank Development Indicators database. This study basically comprises two major analyses. Firstly, using gravity model approach, we analyse the determinants of FDI. Secondly, using a growth model, we also analyse the growth effect of FDI. To investigate determinants and growth impact of FDI, we employ Arellano-Bond dynamic panel system method of moment (GMM) estimator developed by Blundell and Bond (1998). The variables used in this study are categorized into strictly endogenous, exogenous, and instrumental variables. Using panel data under this estimation method reveals several advantages over cross-section analyses (Egger, 1999), allow us to use lagged endogenous variables as predetermine. We use as instruments the two-year lagged endogenous regressors in the estimation and performed one-step estimation of the system GMM.

\subsection{A Gravity Model}

Basically, the gravity concept utilizes the gravitational force concept as an analogy to explain the volume of trade, capital flows, and migration among the countries of the world (Egger, 1999). The gravity model has been used as far back as the early 1960s in order to explain bilateral trade flows. In its basic form, the model was exploring the volume of trade between any two countries or partners are an increasing function of their national incomes and a decreasing function of the distance between them (Dascal et al., 2002). In addition to that authors selected some additional variables for the models. The same concept has been widely used in the analyses related to FDI. The literature on the causes of FDI can be divided into causes of FDI outflows and causes of FDI inflows. Kimura et al. (2007) used gravity concept in order to investigate whether and how aid facilitates FDI. In earlier studies, the gravity type models were applied to either cross-section data, or to single country time series data, which addressed several restrictions on the specification of the model (Haris, 1998). But in the studies from last decade, these models have been adopted to the panel data, which increase the degree of freedom and able to capture country and time effects. In our study, we incorporate panel data to gravity equation-type regression in case of four countries. Our empirical 
study is also based on the idea that home and host country factors together with gravity forces are important in determining FDI flows between the countries. Accordingly, we postulate the following model as:

$$
F D I_{i j t}=\beta_{0}+\beta_{1} g_{i t}+\beta_{2} g_{j t}+\beta_{3} Y_{i t}+\beta_{4} Y_{j t}+\beta_{5} d_{i s t_{i j}}+\beta_{6} V_{i r t}+v_{t}+\varepsilon_{i j t}
$$

Where $F D I_{i j t}$ is $\log$ of total FDI flow from home country $j$ to the host country $i$ in time $t, g_{i t}$ denotes $\log$ of growth rate of host countries, $g_{j t}$ is $\log$ of growth of the home countries whereas $Y_{i t}$ and $Y_{j t}$ denote log of GDP in host and home country respectively; these variables are strictly treated as endogenous variables in the model. Log of distance between home and the host countries is represented by dist $t_{i j}$. It is necessary to include distance variable as a determinant of FDI flows because the transaction costs is expected to increase with the distance. Therefore, we include linear distance between capitals of home and host countries as a proxy for the relative magnitude of the transaction costs, expected to have negative relationship with FDI. $V_{i r t}$ indicates a vector of $r$ variables that influence FDI flow in host countries. $v_{t}$ denotes time effects whereas $\varepsilon_{i j t}$ is white noise error term. The vector comprises $\log$ of population, lnpop, trade openness index, to, human development index, $h d i$, and electricity consumption per capita, $e l$, and exchange rate, $e x$; these are strictly treated as exogenous determinants. Population serves as a proxy variable of market size of host countries, expected to have positive relationship with FDI flows. The openness index expresses the trade liberalization which can also be used as an alternative for risk in host countries (Frenkel et al., 2004). we use human development index serves as one of the encouraging factors, proxied as human capital, which combines three dimensions: 1) life expectancy at birth, as an index of population health and longevity, 2) Knowledge and education, as measured by the adult literacy rate and the combined primary, secondary, and tertiary gross enrollment ratio, and 3) standard of living, as measured by the natural logarithm of gross domestic product per capita purchasing power parity. Electricity consumption per capita serves as proxy variable of infrastructure development, is expected to have positive association with FDI flows in host countries since, infrastructure development motivates private investors to transfer investment to the countries. Exchange rate depreciation enhances location advantage for investment and thus improves FDI in host countries. We also use additional instrumental variables that are not appeared in the model such as inflation, inf, and political freedom index, $p f$.

\subsection{A Growth Model}

Up on investigating growth effects of FDI, we adopt an endogenous growth model type equation which includes capital, labor and human capital as principle factors. The production function of the growth model can be written as:

$$
Y=f\left(Y_{t-1}, K, L, H\right)
$$

Where $Y$ is output level where as $Y_{t-l}$ is lag of output. $K$ denotes physical capital treated as endogenous variable whereas $L$ and $H$ indicate labor force and human capital respectively. Under the assumption that all explanatory variables are positively associated with the output level and technology is constant,, we form an empirical model which reveals the effect of FDI on growth rates of four South Asian countries during the period of 1995-2008 as:

$$
g_{i t}=\beta_{0}+\beta_{1} g_{i t-I}+\beta_{2} X_{i l t}+\beta_{3} Z_{i k t}+v_{i t}
$$

In above equation, $i$ and $t$ denote country and time respectively. $g_{i t}$ is $\log$ of GDP growth rate while $g_{i t-1}$ is its lagged value. $X_{i l t}$ is vector of $l$ endogenous variables, which are assumed to be endogenous due to the causality that run in both directions, includes log of FDI as a percentage of GDP, Infdi, log of foreign aid as a percentage of GDP, lnaid, gross domestic servings as a percentage of GDP, $g s$, and gross domestic capital formation, $g c f . Z_{i k t}$ is vector of $k$ exogenous variables such as labor force, $l f$ and human development index, $h d i$, and $v_{i t}$ indicates stochastic error term. There are some other variables that are not presented in the model used as additional instrumental variables, that are trade openness index, to, exchange rate, $e x$, and political freedom index, $p f$.

\section{The estimation results and interpretation}

We employ system GMM estimates to the models specifications outlined in the previous sections. First, we apply this method to the gravity model given as equation (1) and the results are shown in Table 1. In the first column, shown as specification (1), all the explanatory variables are found to have expected results that FDI is positively influenced by economic growth of host and home countries and the distance variable has negative association with FDI. Human development index, population and electricity consumption per capita are also found to have positive association with FDI. In specification (2), exchange rate is also positively associated with FDI, but human development index is reported as insignificant. As second step, we include time effect which is shown as specification (3), in which some coefficient values are also reported significant and then allow us to conclude that there are common cyclical factors that effect FDI flows in South Asian countries. As third step, we added log of GDPs of home and host countries, respectively, which is shown as specification (4) found to have significant and positive association with FDI flow. This result suggests that business cycles in host and home countries play a crucial role as pulling and pushing factors respectively. In this analysis, interestingly all the exogenous and 
endogenous variables are found to have expected results except log of growth rate in home countries, shown in the specification (3). Concluding this section, the cyclical effects and other principle factors crucially play an important role determining FDI flow into the South Asian countries. However, there is a limitation that needs to be acknowledged in this model that the gravity model that we use excludes some variables that are likely to impact on FDI flow in the case of South Asian countries. For example, nationalization risk, political support, labours cost and cultural similarities and unrest in the host countries.

Turning our attention on investigating magnitude of growth effect of FDI, we employ same estimation method to the equation (2) and the results are presented in Table 2. The specification (1) explores the bench mark results including lagged form of dependent variable suggest that the FDI and aid variables are significant at $\%$ level. Gross saving is found to have insignificant while labor force appear significant at marginal level. We include gross saving in the model because if the developing countries tend to lack the domestic savings required to fund their various investment projects, they must rely on foreign savings. Those savings can come in the form of aid, Bank loans, or direct investment. In this sense, FDI and savings are expected to have positive association. Secondly, we exclude lagged form of dependent variable which is depicted as specification (2) in which aid and labor force variables increase their significant level while FDI remains the same. Interestingly, growth effect of FDI reaches to a relatively more significant level in the presence of aid, which comes under the fact that FDI and aid may have a complementary relationship in these countries. Because, foreign aid plays an essential role fulfilling saving gap, accumulating physical and human capital stock and developing infrastructure in the host countries ( McGillivrary, 2009). Especially, foreign aid inflow in the shape of human capital and infrastructure development can play a vital role by serving as complementary factor to attract much more FDI into the host countries. But if the foreign aid flow is in the shape of physical capital, it will accumulate domestic capital and may serve as substitute to the FDI in the host countries (Selaya and Sunesen, 2008; Gong et al., 2007). Therefore, the results permit us to assume that foreign aid serves as a vehicle facilitating FDI in the South Asian countries. However, more specific studies are needed in this regards. As third step, we include human development index as a proxy for human capital seems to be insignificant shown as specification (3); but still FDI is appeared at the same significant level. We consider human capital variable in the model because according to the endogenous growth theory, the relationship between FDI and human capital is widely seen an important growing topic. Noorbakhsh et al. (2001) suggest that human development becomes major factors that motivate FDI, and the developing countries should formulate policies to improve local skill and builds up their human resources in order to attract more FDI. Therefore, human capital can serve as a complementary factor to FDI, but in this study, it is not significant in the case of South Asian countries. Finally, gross domestic capital formation is replaced for gross savings which is significant at $5 \%$ level but however FDI decreases its significant level. In this analysis, the variable FDI is no longer significant at $1 \%$ level and gives less magnitude effects on growth rates. However, it is a notable fact that which is stable at $5 \%$ level in most part of this analysis except in specification (4). This analysis, thus, permit us to conclude that FDI in South Asian countries are significant and positively associated with growth rate, but seems to be having average supportive to the growth rates in these countries.

\section{Conclusion}

Since our principle objectives were to investigate the determinants and magnitude of growth effect of FDI in South Asian countries, we applied gravity concept for first analysis and endogenous growth concept for the second. We used Arellano-Bond dynamic panel system method of moment (GMM) estimator developed by Blundell and Bond (1998) for both section of analyses. The results suggest that distance and both home and host country characteristics significantly play crucial role in determining the FDI flows into the South Asian region. The cyclical factors in the economies of home and the host countries seem to be an important factor for the magnitude of the FDI flows; not only these but some other factors such as trade openness index, human development index, population and infrastructure are also found to have significant factors motivating FDI inflow in South Asian countries. In addition, FDI flows are inversely related to the distance between the home and the host country supporting the view that distance implies costs associated with FDI activities.

Looking at the growth effect of FDI in these countries, FDI is found to have significant at $5 \%$ level means that the affect of FDI on growth rate is average. Other variables such as foreign aid, labor force and gross domestic capital formation also show their significance at their respective level. Gross domestic savings and human development index are seems to be less important in these countries. FDI seems to have relatively high significant level with foreign aid, comes under the fact that these two variables could be complementary in these countries. Conclusively, our first analysis which investigates the determinants of FDI flow, using a gravity model, explores that the factors are crucially important in determining FDI in South Asian countries. Investigation on the effect of FDI on growth rate, using a growth model, reveals that FDI averagely effects on growth rates in these countries. 


\section{Acknowledgement}

We would like to acknowledge the useful comments of anonymous reviewers to improve this study.

\section{References}

Acemoglu, D. (2008). Introduction to modern economic growth: Parts 1-4, Department of Economics, Massachusetts Institute of Technology, Version 3.

Alfaro, L., Chanda, A., Kalemli-Ozcan, S. and Sayek, S. (2004). FDI and economic growth: the role of local financial markets. Journal of International Economics, 64, 89-112.

Bellak,C., Leibrecht,M. and Riedl, A. (2008). Labor costs and FDI flows into Central and Eastern European Countries: A survey of the literature and empirical evidence. Structural Change and Economic Dynamics, 19, $17-37$.

Beugelsdijk,S., Smeets,R. and Zwinkels, R. (2008). The impact of horizontal and vertical FDI on host's country economic growth. International Business Review, 17, 452-72.

Bezuidenhout, H. (2009). A regional perspective on aid and FDI in Southern Africa. Working paper, No.147, North West University, Potchefstroom, South Africa.

Bitzenisa, A., Tsitouras, A., Vasileios, A. and Vlachos. (2009). Decisive FDI obstacles as an explanatory reason for limited FDI inflows in an EMU member state: The case of Greece. The Journal of Socio-Economics, 38, 691-704.

Borensztein, E., Gregorio, D. J. and Lee, J-W. (1998). How does foreign direct investment affect economic growth? Journal of International Economics, 45, 115-35.

Chakrabory, C. and Nunnenkamp, P. (2008). Economic Reforms, FDI, and Economic Growth in India: A Sector Level Analysis. World Development, 36, 1192-1212.

Dascal, D., Mattas, K. and Tzouvelekas, V. (2002). An analysis of EU wine trade: A gravity model approach. International Advances in Economic Research, 8, 2, 135-47.

Egger, P. (1999). A note on the proper econometric specification of the gravity equation. Economics Letter, 66, 25-31.

Frenkel, M. Funke, K. and Stadtmann, G. (2004). A panel analysis of bilateral FDI flows to emerging economies, Economic System, 28, 281-300.

Gastanaga,V. M., Jeffrey, B. N. and Pashamova, B. (1998). Host country reforms and FDI inflows: How much difference do they make? World Development, 26, 7, 1299-1314.

Harris, M. N. and Mátyás, L. (1998). The Econometrics of Gravity Models. Melbourne Institute Working Paper No.5/98, ISSN.1328-4991.

Herzer, D., Klasen, S. and Nowak-Lehmann, F. D. (2007). In search of FDI-led growth in developing countries: The way forward. Economic Modelling, 25, 793-810.

Javorcik, B. S. (2004). Does Foreign Direct Investment Increase the Productivity of Domestic Firms? In Search of Spillovers through Backward Linkages. The American Economic Review, 94, 605-27.

Ma, X. (2009). An Empirical Analysis on the Impact of FDI on China's Economic Growth. International Journal of Business and Management, 4, N0.6.

McGillivrary, M. (2009). Aid, economic reform, and public sector fiscal behavior in developing countries. Review of Development Economics.1467-9361.00505.x

Merican, Y. (2009). Foreign Direct Investment and Growth in ASEAN-4 Nations. International Journal of Business and Management, 4, N0.6.

Selaya, P and Sunesen, E. R. (2008). Does foreign aid increase foreign direct investment? Discussion Paper, University of Copenhagen, ISSN: 1601-2461

Tuan, C. Linda, F.Y. and Zhao, B. (2009). China's post-economic reform growth: The role of FDI and productivity progress. Journal of Asian Economics, 20, 280-93.

Wei, W. (2005). China and India: Any difference in their FDI performances? Journal of Asian Economics, 16, 719-36.

Whalley, J. and Xin, X. (2009). China's FDI and Non-FDI Economies and the Sustainability of Future High Chinese Growth. China Economic Review, Accepted Manuscript. 
Xing, Y. (2006). Why is China so attractive for FDI? The role of exchange rates. China Economic Review, 17, 198209.

Yao, S. and Wei, K. (2007). Economic growth in the presence of FDI: The perspective of newly industrializing economies. Journal of Comparative Economics, 35, 211-34.

Table 1. Results for Determinants of FDI

\begin{tabular}{|c|c|c|c|c|}
\hline \multirow{3}{*}{$\frac{\text { Variables }}{\text { lngrhost }}$} & \multirow{2}{*}{$(1)$} & \multirow{2}{*}{ (2) } & \multirow{3}{*}{$\begin{array}{c}(3) \\
0.5402 * * *(0.006)\end{array}$} & \multirow{3}{*}{$\begin{array}{c}(4) \\
0.3435 * *(0.053)\end{array}$} \\
\hline & & & & \\
\hline & $0.4893 * * *(0.009)$ & $0.4844 * * * \quad(0.011)$ & & \\
\hline lngrhome & $0.3947 * * \quad(0.047)$ & $0.3045 * * \quad(0.134)$ & $1.2130 * * *(0.000)$ & $-0.2875^{*} \quad(0.120)$ \\
\hline lndist & $-3.9821 * * *(0.000)$ & $-0.0005 * * \quad(0.015)$ & $-3.3322 * * *(0.000)$ & $-0.0003 * *(0.037)$ \\
\hline to & $0.0196^{* *} \quad(0.025)$ & $0.0269 * * * \quad(0.015)$ & $0.0163 * * \quad(0.018)$ & $0.0301 * * *(0.000)$ \\
\hline lnpop & $1.4864 * * * \quad(0.000)$ & $1.3275 * * * \quad(0.000)$ & $1.2261^{* * *} \quad(0.000)$ & \\
\hline$h d i$ & $0.1565^{* * *} \quad(0.000)$ & $(0.629)$ & $0.0901 * * * \quad(0.002)$ & \\
\hline el & $0.0027^{* * *} \quad(0.000)$ & $0.0020 * *$ & & \\
\hline$e x$ & & $0.0107 * *$ & & \\
\hline lngdphost & & & & $1.2419 * * *(0.000)$ \\
\hline lngdphome & & & & $1.4363 * * *(0.000)$ \\
\hline D_1996 & & & $0.5297 * * \quad(0.019)$ & \\
\hline D_1997 & & & $1.4930 * * *(0.000)$ & \\
\hline D_1998 & & & $(0.493)$ & \\
\hline D_-1999 & & & $0.5078 * * \quad(0.026)$ & \\
\hline D_2000 & & & $0.5803 * * \quad(0.015)$ & \\
\hline D_2001 & & & $-0.2239 \quad(0.494)$ & \\
\hline D_2002 & & & $(0.336)$ & \\
\hline D_2003 & & & $(0.558)$ & \\
\hline D_2004 & & & $0.7549 * * *(0.002)$ & \\
\hline D_2005 & & & $0.7209 * * *(0.004)$ & \\
\hline D_2006 & & & $1.2178 * * *(0.000)$ & \\
\hline D_2007 & & & $1.3932 * * *(0.000)$ & \\
\hline D_2008 & & & $1.0540 * * *(0.000)$ & \\
\hline Constant & $22.9232 * * * \quad(0.009)$ & $-5.0780 * * \quad(0.065)$ & $23.4027 * * *(0.003)$ & $-27.7616^{* * *}(0.000)$ \\
\hline F-test & 99.06 & 85.12 & 61.55 & 117.18 \\
\hline Prob $>F$ & 0.000 & 0.000 & 0.000 & 0.000 \\
\hline Sargan test-chi ${ }^{2}$ & 101.59 & 100.64 & 100.28 & 93.04 \\
\hline
\end{tabular}

$*, * *, * *$ Denotes significance at a $10 \%, 5 \%, 1 \%$ level, respectively. $P$ values are shown as (.). We apply xtabond 2 command in Stata for system GMM estimation developed by David Roodman

Table 2. Results for Growth Effect of FDI

\begin{tabular}{|c|c|c|c|c|c|c|}
\hline Variables & \multicolumn{2}{|c|}{ (1) } & (2) & \multicolumn{2}{|c|}{ (3) } & \multirow[t]{2}{*}{ (4) } \\
\hline $\operatorname{lng} r_{t-1}$ & $0.1987 *$ & $(0.201)$ & & & & \\
\hline $\ln f d i$ & $0.1437 * *$ & $(0.099)$ & $0.1594 * * \quad(0.018)$ & $0.1438 * *$ & $(0.060)$ & $0.1018 *(0.188)$ \\
\hline lnaid & $0.3282 * *$ & $(0.057)$ & $0.4067 * * *(0.005)$ & $0.3972 * * *$ & $(0.007)$ & $0.2990 * *(0.059)$ \\
\hline$g s$ & 0.02182 & $(0.223)$ & $0.0223 * \quad(0.161)$ & 0.0201 & $(0.227)$ & \\
\hline lf & $1.6000^{*}$ & $(0.158)$ & $2.1706^{* *} \quad(0.022)$ & $2.2600 * *$ & $(0.021)$ & $1.8400 * *(0.056)$ \\
\hline$h d i$ & & & & 0.0056 & $(0.663)$ & \\
\hline$g c f$ & & & & & & $0.0245^{* *}(0.070)$ \\
\hline F-test & 5. & & 7.62 & 6.0 & & 8.15 \\
\hline Prob $>F$ & 0.0 & & 0.000 & 0.00 & & 0.000 \\
\hline Sargan test-chi ${ }^{2}$ & 44 & & 58.56 & 58.9 & & 58.54 \\
\hline
\end{tabular}

$*, * *, * * *$ Denotes significance at a $10 \%, 5 \%, 1 \%$ level, respectively. $P$ values are shown as (.). 


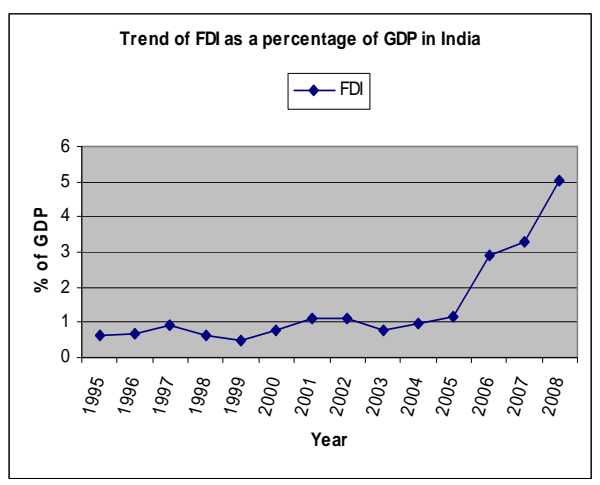

Figure 1.

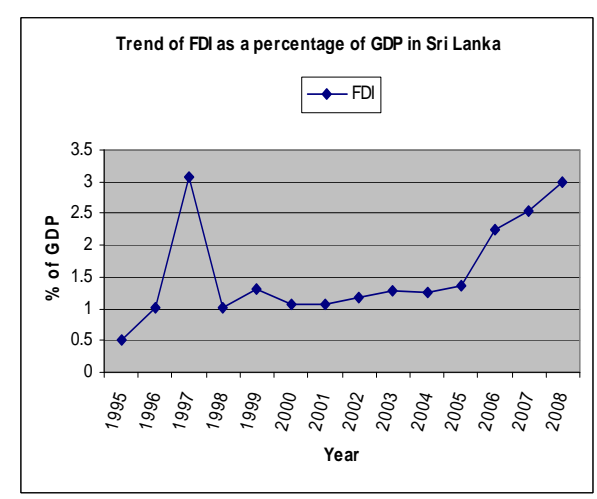

Figure 3

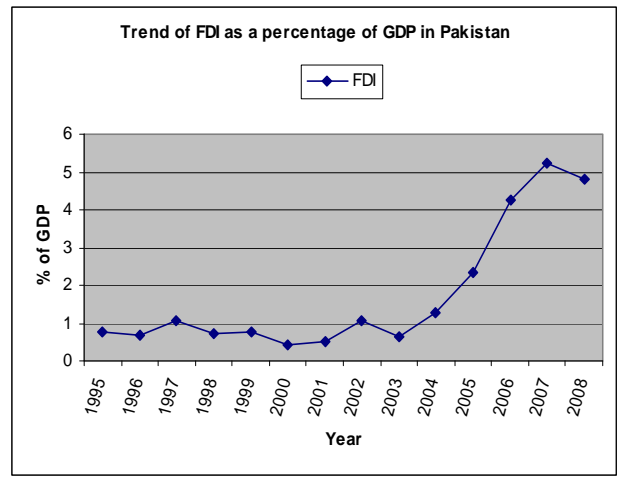

Figure 2

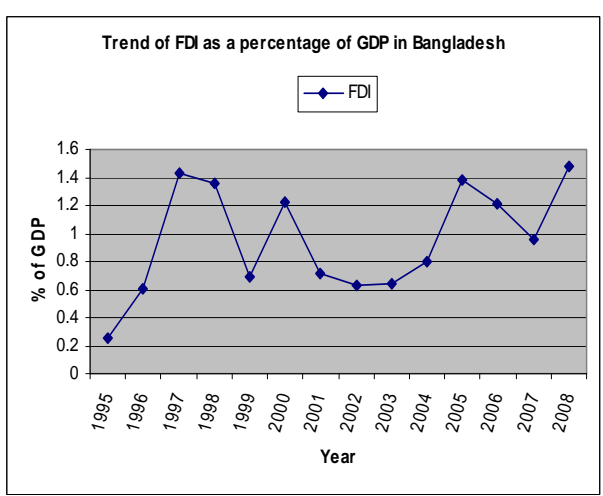

Figure 4 